\title{
Career Satisfaction among Specialist Dental Practitioners in the Kingdom of Saudi Arabia
}

\author{
Noor Nassif ${ }^{1}$, Rana Abunemer ${ }^{2},{\text { Reem } \text { Ali }^{3}, \text { Bushra Sunbali }^{4} \text {, Sara AlShammaery }}^{5}$
}

\begin{abstract}
Aim: To ascertain empirically the level of career satisfaction and the factors affecting it to achieve a work-life balance.

Materials and methods: A cross-sectional study was conducted among dental specialists in Saudi Arabia, using a 25-item online survey questionnaire through emails, social media, and direct interview technique. The questionnaire included factors that measure the job satisfaction in dentistry, like working hours per day, work-life balance, income level, environment of workplace, self-improvement, attitude, and respect from the patient and the society. Data were analyzed using SPSS.

Results: Of 315 respondents, the majority were Saudis (68.6\%) and males (72.7\%). Most of them were satisfied with their work-life balance (63.2\%). Almost half of the respondents were satisfied with their current workplace and the opportunities they were offered. Further analysis revealed that most of the respondents will not change their specialty (67.7\%) and would recommend their specialty to senior dental students (74.6\%). Conclusion: This study showed an acceptable level of satisfaction in almost every aspect (environmentally, psychologically, physically, financially, socially, and personally), great outcomes, and job performance. Nevertheless, some dissatisfaction was identified in the work environment which had a great effect on the overall satisfaction including the availability of materials, the continuous progression in learning and career development, salary, and top officials.

Keywords: Career satisfaction, Dental practitioner, Patient attitude, Work environment, Work-life balance.

Journal of Oral Health and Community Dentistry (2021): 10.5005/jp-journals-10062-0093
\end{abstract}

\section{INTRODUCTION}

Job satisfaction (JS) is conceptualized as a general attitude toward one's job and contentment with it. ${ }^{1}$ One of the most widely used definitions in organizational research is that of Locke, who defines JS as "a pleasurable or positive emotional state, resulting from the appraisal of one's job or job experiences."2 Satisfaction is highly related to the job and career attrition and is ultimately related to job performance and patient care. ${ }^{3}$

Low JS of dentists can lead to high turnover with resultant loss of productivity and reduced quality of patient care. ${ }^{4}$ One question that is put frequently to dentists is, "If you had it to do over again, would you become a dentist?"5 Dentists' knowledge and attitude toward patients, availability of equipment, patient satisfaction toward dentists, continuous professional development opportunities, and dentists' work experience are some factors influencing the success of a dental practice and JS among dentists. ${ }^{6,7}$ Thus, the present study is undertaken to ascertain empirically the level of career satisfaction and the factors affecting it to achieve a work-life balance.

\section{Materials and Methods}

A cross-sectional survey using a self-administered questionnaire was conducted among dental specialists in Saudi Arabia by using e-survey Google forms that were widely spread throughout the population. The questionnaire was done both in Arabic and English languages. Ethical approval was obtained from the Research Center of Riyadh Elm University and the institutional review board (FUGRP/ 2018/236).

The questionnaire composed of 25 questions, including the factors that measure the JS in dentistry, such as, working hours per day, work-life balance, income level, workplace environment,
${ }^{1-4}$ College of Dentistry, Riyadh Elm University, Riyadh, Kingdom of Saudi Arabia

${ }^{5}$ Department of Operative Dentistry, College of Dentistry, Riyadh Elm University, Riyadh, Kingdom of Saudi Arabia

Corresponding Author: Rana Abunemer, College of Dentistry, Riyadh Elm University, Riyadh, Kingdom of Saudi Arabia, Phone: +966 53922 5242, e-mail: rana.m.abunmer@student.riyadh.edu.sa

How to cite this article: Nassif N, Abunemer R, Ali R, et.al. Career Satisfaction among Specialist Dental Practitioners in the Kingdom of Saudi Arabia. J Oral Health Comm Dent 2021;15(1):41-43.

Source of support: Nil

Conflict of interest: None

self-improvement, attitude, and respect from the patient and the society. Descriptive statistics, such as frequency, distribution, and percentages were calculated for all demographic variables and questionnaire items. The relationship between the demographic variables and the questionnaire items was assessed by applying a chi-square test. A value of $p \leq 0.05$ was considered statistically significant. Data were analyzed using IBM SPSS Statistics for Windows, version 25.0 (IBM Corp, Armonk, New York, USA).

\section{Results}

Of 315 respondents, the majority were males (72.7\%). Most of the specialists were between the ages of 31 and 40 (51.7\%), and over one-third had 3-8 years of experience (35.4\%). Furthermore, around two-thirds were Saudis (68.6\%) and living in the Riyadh region (65.6\%). Over half of them (54.6\%) pursued their specialty in Saudi Arabia. Most of them (62.7\%) work in public clinics. Just over half 
of them (53\%) work less than 8 hours/day. Descriptive analysis of demographic characteristics is shown in Table 1. Figure 1 shows the distribution of respondents by specialty.

Work-life balance showed satisfaction among $63.2 \%$ of the respondents (Fig. 2). Moreover, 56.5\% were satisfied with their workplace and $52.7 \%$ believed that adequate career enhancement opportunities are gained in their current workplace. When specialists were asked if they would recommend their specialty to seniors, $74.6 \%$ agreed.

Over half $(57.5 \%)$ of the specialists agreed that they took into consideration the country's need when they chose their specialty. When asked if they would reconsider changing their specialty, $67.6 \%$ reported they will not change their specialty. On the other aspect, $67.6 \%$ were contented by the respect and patient attitude toward them. Lastly, $48.3 \%$ reported that a full devotement to work would affect a specialist's personal life in a harmful manner. Association between respondents' satisfaction by specialty are shown in Figure 3 .

At the end of the survey, specialists were given an open question to discuss the most unsatisfied things about their work environment, and the answers were concluded with the most repeated responses as follows: overloading with tasks, long working hours, stress, faculty and workmates' attitude, facilities, materials, and human resources, salary, lack of patient cooperation and education, and inflexible work manager.

\section{Discussion}

Several local studies have addressed JS among healthcare professionals in Saudi Arabia, mostly among nurses and/or physicians. ${ }^{8-11}$ Their reported findings varied considerably across
Table 1: Demographics

\begin{tabular}{llcl}
\hline & & Frequency & Percentage \\
\hline Gender & Male & 229 & 72.2 \\
Nationality & Female & 86 & 27.8 \\
& Saudi & 216 & 68.5 \\
Age (years) & Non-Saudi & 99 & 31.5 \\
& $\leq 30$ & 82 & 26.0 \\
& $31-40$ & 163 & 51.7 \\
Current workplace & $41-50$ & 23 & 14.9 \\
Working hours/day & Public & 197 & 7.3 \\
& Private & 117 & 62.7 \\
Years of experience & $\leq 8$ hours & 167 & 37.3 \\
& $>8$ hours & 148 & 53.0 \\
& $<3$ & 63 & 47.0 \\
& $3-8$ & 111 & 20.1 \\
& $9-15$ & 83 & 35.4 \\
& $16-25$ & 57 & 18.2 \\
\hline
\end{tabular}

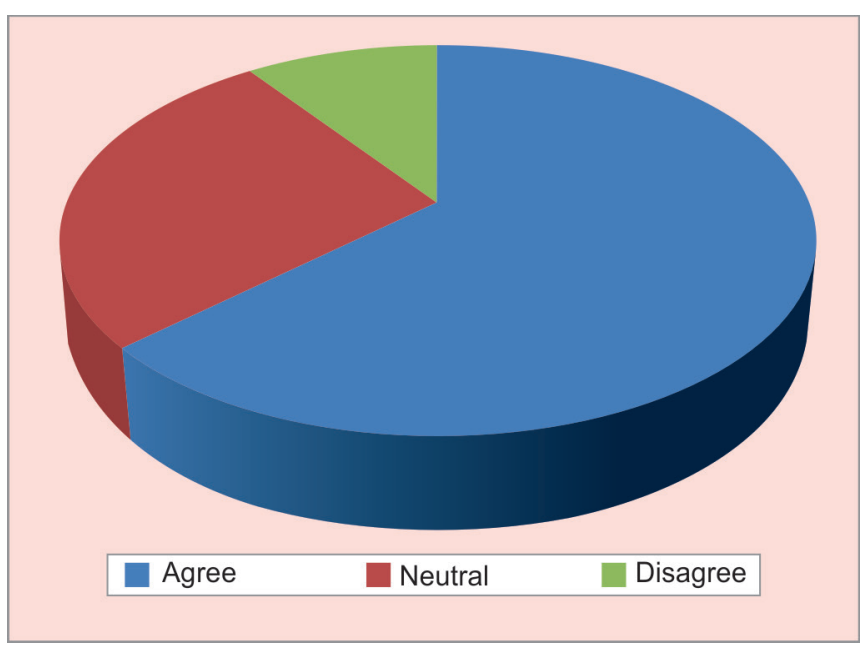

Fig. 2: Respondents' satisfaction with work-life balance

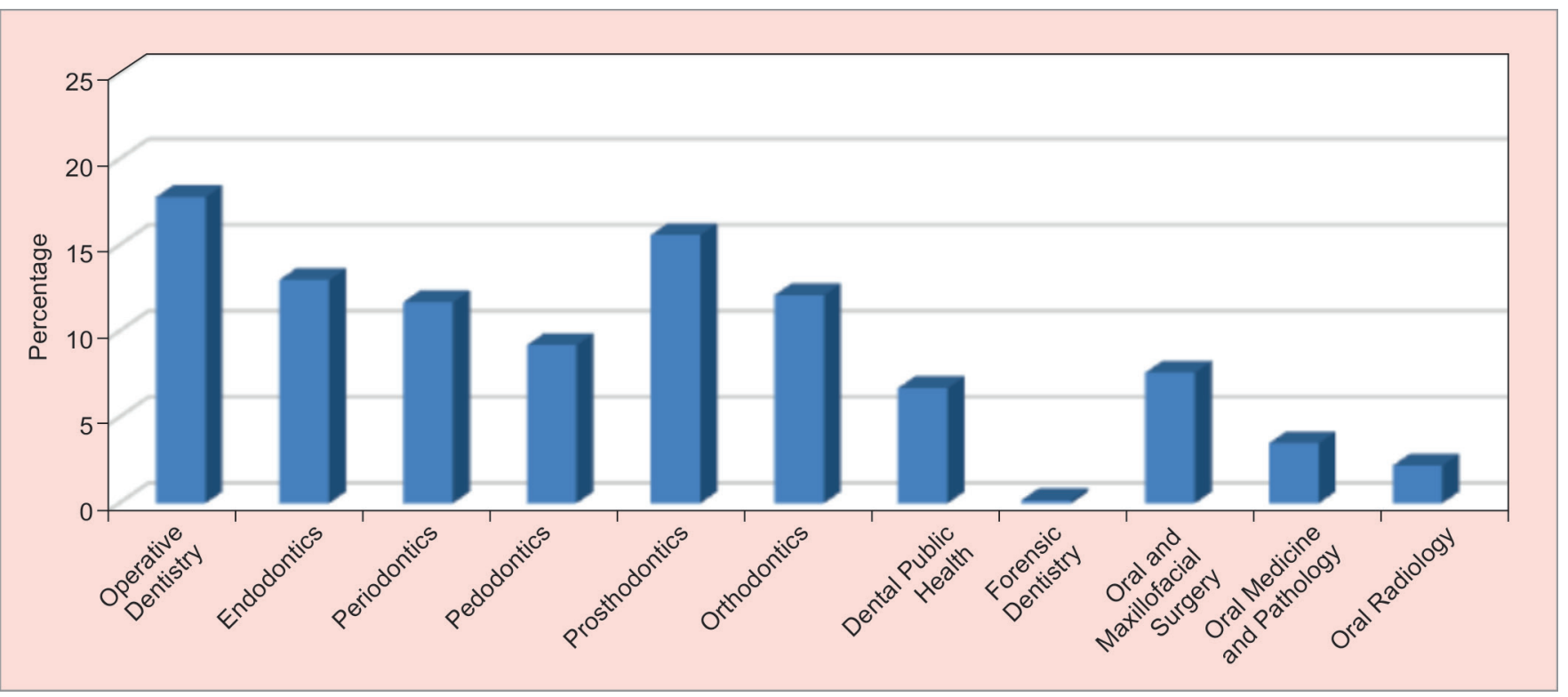

Fig. 1: Distribution of participants by specialty 


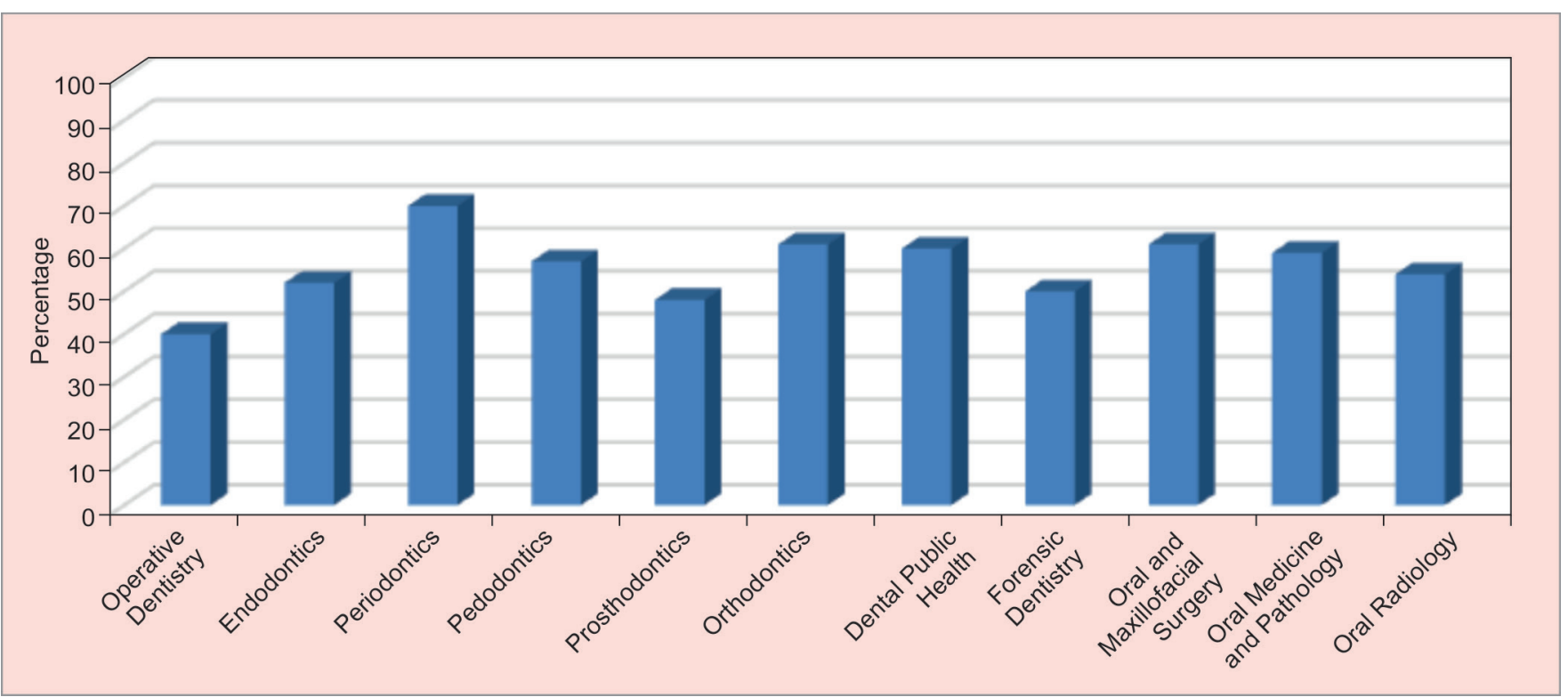

Fig. 3: Respondents' satisfaction by specialty

different occupational settings and professional groups. We have not come across any study on JS among dental specialists. The primary purpose of this study is to point out career satisfaction in each specialty for further life-work balance by measuring different aspects and factors that could affect it.

A total of 315 dental specialists were involved as a study group in this research and according to that, the following findings were built in consonance with their answers. Depending on the analysis, the most satisfying specialty among the included ones was periodontics followed by an almost equal percentage between orthodontics and oral and maxillofacial surgery. This result is supported by the past research that showed (80.7\%) satisfaction among orthodontists with their profession irrespective of gender grouping. ${ }^{12}$ On the contrary, operative dentistry and prosthodontics were the least satisfied. It should be noted that this result goes along with lacking equipment and materials and, since a great majority of participants were from the operative department, it played a major role.

Similarly, satisfaction percentages were roughly given to each specialty from the most to the least as follows: periodontics (70\%), orthodontics (61\%), oral and maxillofacial surgery (61\%), public health $(60 \%)$, oral medicine and pathology $(59 \%)$, pedodontics (57\%), oral radiology (54\%), endodontics $(52 \%)$, forensic dentistry (50\%), prosthodontics (48\%), and operative dentistry (40\%). Taking another aspect of concern regarding the working sector, private clinic workers are more satisfied than public ones. In light of country needs and work-life balance, it is easy to see a proximate percentage between specialists' satisfaction and the ones who thought about country needs at that time, suggesting that it is important to choose a specialty depending on the field demands and obligations in order to achieve a balance and the satisfaction wanted.

\section{ConcLusion}

This study showed an acceptable level of satisfaction in almost every aspect (environmentally, psychologically, physically, financially, socially, and personally), great outcomes, and job performance. Nevertheless, some dissatisfaction was identified in the work environment which had a great effect on the overall satisfaction including the availability of materials, the continuous progression in learning and career development, salary, and top officials.

\section{References}

1. Wanous JP, Lawler EE. Measurement and meaning of job satisfaction. J Appl Psychol 1972;56(2):95. DOI: 10.1037/h0032664.

2. Locke EA. The nature and causes of job satisfaction. In: Handbook of industrial and organizational psychology; 1976.

3. Bader JD, Sams DH. Factors associated with job and career satisfaction among dental hygienists. J Public Health Dent 1992;52(2):43-51. DOI: 10.1111/j.1752-7325.1992.tb02242.x.

4. Luzzi L, Spencer AJ, Jones $K$, et al. Job satisfaction of registered dental practitioners. Aust Dent J 2005;50(3):179-185. DOI: 10.1111/j.18347819.2005.tb00358.x.

5. Chambers DW. The role of dentists in dentistry. J Dent Educ 2001;65(12):1430-1440.

6. Kaipa S, Pydi SK, Krishna Kumar RV, et al. Career satisfaction among dental practitioners in Srikakulam, India. J Int Soc Prev Community Dent 2015;5(1):40-46. DOI: 10.4103/2231-0762.151976.

7. Roth SF, Heo G, Varnhagen C, et al. Job satisfaction among Canadian orthodontists. Am J Orthod Dentofacial Orthop 2003;123(6):695-700. DOI: 10.1016/s0889-5406(03)00200-2.

8. el-Gilany A, Al-Wehady A. Job satisfaction of female Saudi nurses. East Mediterr Health J 2001;7(1-2):31-37.

9. Al-Aameri AS. Job satisfaction and organizational commitment for nurses. Saudi Med J 2000;21(6):531-535.

10. Al Juhani AM, Kishk NA. Job satisfaction among primary health care physicians and nurses in Al-madinah Al-munawwara. J Egypt Public Health Assoc 2006;81(3-4):165-180.

11. Kalantan KA, Al-Taweel AA, Abdul Ghani H. Factors influencing job satisfaction among primary health care (PHC) physicians in Riyadh, Saudi Arabia. Ann Saudi Med 1999;19(5):424-426. DOI: 10.5144/02564947.1999.424.

12. Alqahtani ND, Alshehry $\mathrm{K}$, Alateeq $\mathrm{S}$, et al. An assessment of job satisfaction: a cross-sectional study among orthodontists of Saudi Arabia. J Orthod Sci 2018;7:4. DOI: 10.4103/jos.JOS_77_17. 